\title{
In vitro immunomodulatory potential of Artemisia indica Willd. in chicken lymphocytes
}

\author{
Pushpa Ruwali ${ }^{1}$, Tanuj Kumar Ambwani² and Pankaj Gautam ${ }^{1}$
}

1. Department of Biotechnology, Graphic Era University, Dehradun - 248 002, Uttarakhand, India; 2. Department of Veterinary Physiology and Biochemistry, College of Veterinary \& Animal Sciences, G. B. Pant University of Agriculture \& Technology, Pantnagar - 263 145; Uttarakhand, India.

Corresponding author: Tanuj Kumar Ambwani, e-mail: tambwani@yahoo.com

Co-authors: PR: pushparuwali@gmail.com, PG: gautampankaj76@gmail.com

Received: 11-08-2017, Accepted: 12-12-2017, Published online: 28-01-2018

doi: 10.14202/vetworld.2018.80-87 How to cite this article: Ruwali P, Ambwani TK, Gautam P (2018) In vitro immunomodulatory potential of Artemisia indica Willd. in chicken lymphocytes, Veterinary World, 11(1): 80-87.

\begin{abstract}
Aim: Evaluation of the in vitro immunomodulatory potential of Artemisia indica Willd. methanolic extract in chicken lymphocyte culture system through lymphocyte (B and $\mathrm{T}$ cells) proliferation assay, after standardizing the maximum noncytotoxic dose (MNCD) in chicken lymphocytes.

Materials and Methods: Fresh aerial parts of A. indica Willd. (family: Asteraceae) specimens were collected (altitude $1560 \mathrm{~m}$ ), gotten authenticated, processed, dried, and Soxhlet extracted to yield methanolic extract (AME). Chicken splenocytes were isolated from spleens collected from healthy birds; lymphocytes were separated by density gradient centrifugation, percentage cell viability determined and final cell count adjusted to $10^{7} \mathrm{cells} / \mathrm{ml}$ in RPMI-1640 medium. MNCD of AME in chicken lymphocytes was determined through 3-(4,5-dimethylthiazol-2-y1)-2,5-diphenyltetrazolium bromide dye reduction assay. Immunomodulatory potential of AME was evaluated through lymphocytes proliferation or B and $\mathrm{T}$ cells blastogenesis assay in the presence of appropriate mitogens, namely, lipopolysaccharide (LPS) and concanavalin A (Con A), respectively.

Results: Maximum concentration of AME exhibiting 100\% cell viability (MNCD) was $200 \mu \mathrm{g} / \mathrm{ml}$ and was selected for further in vitro analysis. The in vitro exposure of chicken lymphocytes to $200 \mu \mathrm{g} / \mathrm{ml}$ dose of AME, resulted in significant $(\mathrm{p}<0.05)$ upregulation of $11.76 \%$ in B cell proliferation in the presence of B cell mitogen (LPS) and a significant ( $<<0.05)$ increase of $12.018 \% \mathrm{~T}$ cells proliferation in the presence of the mitogen (Con A), as compared to the control.

Conclusion: The significant upregulation in the proliferation of two major cell types modulating the immune system is an indication of the immunostimulatory potential of the plant. It would be worthwhile to further evaluate $A$. indica on relevant immunomodulatory aspects, especially the in vivo studies in a poultry system.
\end{abstract}

Keywords: Artemisia indica Willd., immunomodulation, in vitro chicken lymphocytes, lymphocyte proliferation assay, plant extract.

\section{Introduction}

The immune system, more than any other system in the body, is central to one's health and well-being because it affects every other part of the body. Immune system is not only crucial to homeostasis; it plays a key role in the defense against infections and cancers. Its integrity and efficiency are important during chemotherapeutic intervention for the treatment of many diseases [1]. Immunomodulation is a procedure that can alter the immune system of an organism by interfering with its function. If it results in an enhancement/decrease of immune reaction, it is named as "Immunomodulatory" [2].

Plants have played a significant role in maintaining human and animal health and improving the

Copyright: Ruwali, et al. Open Access. This article is distributed under the terms of the Creative Commons Attribution 4.0 International License (http://creativecommons.org/licenses/by/4.0/), which permits unrestricted use, distribution, and reproduction in any medium, provided you give appropriate credit to the original author(s) and the source, provide a link to the Creative Commons license, and indicate if changes were made. The Creative Commons Public Domain Dedication waiver (http://creativecommons.org/ publicdomain/zero/1.0/) applies to the data made available in this article, unless otherwise stated. quality of life for thousands of years. Modulation of immune responses to alleviate disease has been one mechanism of interest. A number of medicinal plants have been shown to stimulate or inhibit the immune system [3].

A medicinal plant genus Artemisia (Asteraceae), popularly known as "Sage Brush" or "Wormwood," has been used extensively in folk medicine and as food by many cultures since times immemorial [4]. A good amount of literature is available proclaiming the ethnoveterinary usage of Artemisia species throughout world including India, China, Japan, Pakistan, several middle-east, and African countries, in livestock including poultry as anthelmintic, antiprotozoal for blood parasite (both intra- and extra-cellular), anticoccidial, acaricidal, antispasmodic, diuretic, and cholagogue, against veterinary tumors and sarcomas and as fodder for ruminants [5].

Artemisia is a diverse and economically important genus, and it has more than 500 species reported in the world and out of which about 47 species, are found in India [6,7]. In India, Artemisia indica Willd. (hereinafter $A$. indica) vernacularly known as "titépâti," is a 
perennial herb found in the western Himalayas and is one of the most utilized locally as a traditional medicinal plant and animal feed, especially in the Kumäun hills (Uttarakhand, India), though, surprisingly, is also one of the lesser studied one [4]. A fair number of reports confirm the use of $A$. indica as a culinary herb and a food plant all over the world, including India, Pakistan, Nepal, and Japan. Ethnomedicinally, $A$. indica has been employed by local people to alleviate chronic fever, dyspepsia, hepatobiliary ailments, as well as an anthelmintic, antiseptic, antispasmodic, emmenagogue, expectorant, and stomachic $[4,8]$. Members of the genus Artemisia have been known to possess phytochemicals responsible for its immunomodulatory potential [3]. Numerous species of Artemisia have been reported to exhibit anti-inflammatory activity [9-11].

According to the WHO, across the world, traditional medicine is either the mainstay of health care delivery or serves as a complement to it. Traditional medicines, of proven quality, safety, and efficacy, contribute to the goal of ensuring that all people have access to care. For many millions of people, herbal medicines, traditional treatments, and traditional practitioners are the main source of health care, and sometimes the only source of care. This is care that is close to homes, accessible, and affordable. It is also culturally acceptable and trusted by large numbers of people. The affordability of most traditional medicines makes them all the more attractive at a time of soaring healthcare costs and nearly universal austerity. Traditional medicine also stands out as a way of coping with the relentless rise of chronic non-communicable diseases [12]. Hence, the need for the search for newer herbal sources and more importantly the validation of their ethnomedicinal claims on the modern scientific platform.

Meager information is available on the immunomodulatory activity of $A$. indica. In spite of sincere efforts, authors could not find any reports on the in vitro immunological studies of $A$. indica extracts in avian system, and to the best of the knowledge, the present communication is the first report of the in vitro immunomodulatory potential of $A$. indica Willd. extract in chicken lymphocytes.

\section{Materials and Methods}

\section{Ethical approval}

This research was carried out after procuring the necessary approval from the Institutional Animal Ethics Committee, College of Veterinary and Animal Sciences, Govind Ballabh Pant University of Agriculture and Technology, Pantnagar, Uttarakhand, India.

\section{Plant material and preparation of plant extract}

Fresh aerial parts of $A$. indica Willd. (family: Asteraceae) specimens were collected at an altitude of $1560 \mathrm{~m}$, strictly abiding by the standard precautions in the month of June from the Kumäuñ hills of
Okhalkanda block (latitude $29^{\circ} 39^{\prime} \mathrm{N}$ and longitude $79^{\circ} 67^{\prime}$ E), near Bhimtal, district Nainital, Uttarakhand (India). The plant specimens were authenticated in the Botanical Survey of India (BSI), Northern Circle, Dehradun (Uttarakhand). A voucher specimen (Acc. no. 114879) was deposited at the herbarium of BSI. The extraction of dried and finely powdered plant material was done by Soxhlet extraction $(1: 10 \mathrm{w} / \mathrm{v}$ extract: solvent) with methanol to yield $A$. indica methanol extract (AME). Extract preparation in detail is described elsewhere [4].

\section{Chicken lymphocytes isolation and cell viability assay}

Chicken splenocytes were isolated from spleens collected from healthy birds, under laminar air flow as per standard procedure [13]. Lymphocytes were separated by density gradient centrifugation (HisepLSM, HiMedia, India) as per the method described by Rose and Friedman [14]. Percentage cell viability was determined by $0.1 \%$ Trypan blue dye exclusion test using hemocytometer [15], and final cell count was adjusted to $10^{7}$ cells/ml in RPMI-1640 medium with antibiotic and antimycotic solution supplemented with $10 \%$ Fetal Bovine Serum (all HiMedia, India).

\section{Determination of non-cytotoxic dose of AME in chicken lymphocyte cell culture system}

The isolated lymphocytes were exposed to various dilutions of AME (prepared in RPMI- 1640) in triplicate in 96 well tissue culture plate. Maximum non-cytotoxic dose (MNCD) of AME in chicken lymphocytes was determined through 3-(4,5-dimethylthiazol-2-y1)-2,5- diphenyltetrazolium bromide (MTT) (Sigma) dye reduction assay [16]. The extract (AME) was used in concentrations ranging from $0.1 \mu \mathrm{g} / \mathrm{ml}$ to $1.6 \mathrm{mg} / \mathrm{ml}$ (namely, $0.1 \mu \mathrm{g} / \mathrm{ml}, 0.5 \mu \mathrm{g} / \mathrm{ml}, 1 \mu \mathrm{g} / \mathrm{ml}$, $5 \mu \mathrm{g} / \mathrm{ml}, 10 \mu \mathrm{g} / \mathrm{ml}, 50 \mu \mathrm{g} / \mathrm{ml}, 100 \mu \mathrm{g} / \mathrm{ml}, 200 \mu \mathrm{g} / \mathrm{ml}$, $300 \mu \mathrm{g} / \mathrm{ml}, 400 \mu \mathrm{g} / \mathrm{ml}, 500 \mu \mathrm{g} / \mathrm{ml}, 600 \mu \mathrm{g} / \mathrm{ml}, 700$ $\mu \mathrm{g} / \mathrm{ml}, 800 \mu \mathrm{g} / \mathrm{ml}, 900 \mu \mathrm{g} / \mathrm{ml}, 1 \mu \mathrm{mg} / \mathrm{ml}, 1.2 \mathrm{mg} / \mathrm{ml}$, $1.4 \mathrm{mg} / \mathrm{ml}$, and $1.6 \mathrm{mg} / \mathrm{ml}$ ). The maximum concentration of AME showing $100 \%$ cell viability (MNCD) in comparison to control was selected for further experimentations.

\section{Determination of AME induced immunomodulation through lymphocytes proliferation assay}

Immunomodulatory potential of AME was evaluated through lymphocytes proliferation or $\mathrm{B}$ and $\mathrm{T}$ cells blastogenesis assay in the presence of appropriate mitogens, namely, lipopolysaccharide (LPS, Sigma) and concanavalin A (Con A, HiMedia). Lymphocyte proliferation assay (LPA) was carried out as per the method described by Lee et al. [17]. Briefly, the cells were cultured in wells (in triplicate) using $100 \mu \mathrm{l}$ of cell suspension in the presence of either LPS or Con A in respective wells of 96 well flat bottom sterile microtiter plate in the presence and absence of AME. The plate was sealed with protective cellophane tape and was incubated for $68 \mathrm{~h}$ at $37^{\circ} \mathrm{C}$ in $5 \% \mathrm{CO}_{2}$ gas tension in the incubator. At the end of the incubation, $50 \mu 1$ of MTT $(5 \mathrm{mg} / \mathrm{ml})$ dye was added to all the 
wells under a sterile condition in the laminar air flow and further incubated for $4 \mathrm{~h}$ at $37^{\circ} \mathrm{C}$ in $5 \% \mathrm{CO}_{2}$ gas tension. Contents of the plate were removed slowly, and $100 \mu \mathrm{l}$ of dimethyl sulfoxide was added to all the wells and mixed by gentle pipetting.

The absorbance of each well was measured at $570 \mathrm{~nm}$ wavelength using Microplate ELISA Reader. Mean optical density (O.D.) was calculated by subtracting mean O.D. of control wells from the mean O.D. of mitogen-stimulated culture wells, as per the following formula.

Mean optical density (O.D.)=Mean O.D. of mitogen-stimulated culture well-Mean O.D. of control

\section{Statistical analysis}

All experiments were performed in triplicate and data were reported as mean \pm standard deviation. The relevant data were statistically analyzed by CRD (completely randomized block design) using ANOVA [18]. The critical difference at 5\% $(\mathrm{p}<0.05)$ level of significance for each character was worked out for comparing the significance of the treatment means. The differences between the control group and treatment groups were determined using t-test and $\mathrm{p}<0.05$ was regarded as significantly different.

\section{Results}

The AME was assessed for it's in vitro immunomodulatory potential in chicken lymphocytes culture, and for any such in vitro cell culture studies, it becomes imperative to standardize the "non-cytotoxic dose" in the selected system.

\section{Non-cytotoxic dose of AME in chicken lymphocytes culture}

The chicken lymphocytes were exposed to various dilutions of AME to determine its MNCD for ensuing in vitro studies. The results obtained are presented in Table-1 and Figure-1. The data indicated dose-dependent cytotoxicity induced by AME in chicken lymphocytes culture, namely, higher the concentrations of AME, i.e., ranging from $0.3 \mathrm{mg} / \mathrm{ml}$ to $1.6 \mathrm{mg} / \mathrm{ml}$, more was the cytotoxicity. AME displayed maximum cytotoxicity at the highest concentration of $1.6 \mathrm{mg} / \mathrm{ml}$ used in the study with $54.72 \%$ cytotoxicity. AME concentrations ranging from $0.2 \mathrm{mg} / \mathrm{ml}$ $(200 \mu \mathrm{g} / \mathrm{ml})$ to $0.0001 \mathrm{mg} / \mathrm{ml}(0.01 \mu \mathrm{g} / \mathrm{ml})$ showed $100 \%$ cell viability. Since the maximum concentration of AME that showed $100 \%$ cell viability was $0.2 \mathrm{mg} /$ $\mathrm{ml}(200 \mu \mathrm{g} / \mathrm{ml})$, thus it was selected for further in vitro analysis. This MNCD $(200 \mu \mathrm{g} / \mathrm{ml})$ for AME was then used for evaluation of its immunomodulatory potentials through $\mathrm{B}$ and $\mathrm{T}$ cells proliferation in the presence of respective mitogens, namely, LPS (B cells) and Con A (T cells).

\section{Effect of AME on B cells proliferation}

The results of in vitro effects of AME on B cell proliferation in chicken lymphocytes are depicted in Table-2 and Figure-2. The in vitro exposure of chicken lymphocytes to $200 \mu \mathrm{g} / \mathrm{ml}$ dose of AME, showed 
significant $(p<0.05)$ increase of $11.76 \%$ in B cell proliferation in the presence of B cell mitogen (LPS).

\section{Effect of AME on $\mathrm{T}$ cells proliferation}

AME treated cells displayed a significant $(p<0.05)$ increase of $12.018 \% \mathrm{~T}$ cells proliferation as compared to the control in the presence of the mitogen (Con A) (Table-3 and Figure-3).

\section{Discussion}

Poultry is an important source of food and nutrition not only in ethnic and tribal societies since ancient history but also in the developed world today. Birds have played a central role in many biological disciplines, particularly ecology, evolution, and behavior. The chicken, as a model vertebrate, also represents an important experimental system for developmental biologists, immunologists, cell biologists, and geneticists [19]. Besides this, Indian Poultry Industry is 5000 years old and has been providing nutritional security to the poor and also offering employment to millions of people in rural and urban areas [20]. All this formed the motivational ground to choose chicken as the animal model system for evaluating the immunomodulatory potential of $A$. indica.

Immunomodulation is one of the main targets for synthetic drugs and chemicals. However, its high cost, anticipated toxicity, and adverse effects render it undesirable for patients. In contrast, the use of herbal plants as health promoters is gaining increasing attention in both consumers and scientific circles [21]. Plants produce a great variety of organic compounds that are not directly involved in primary metabolic processes of growth and development. The roles these natural products or secondary metabolites play in plants have only recently come to be appreciated in an analytical context of modern science [22]. In recent years, the medicinal values of phytochemicals have aroused much concern, especially as immunomodulators or agents used for the adjunctive treatment of cancer [23].

Members of the genus Artemisia have been reported to possess phytochemicals responsible for its immunomodulatory potential, with the majority of reports describing its anti-inflammatory

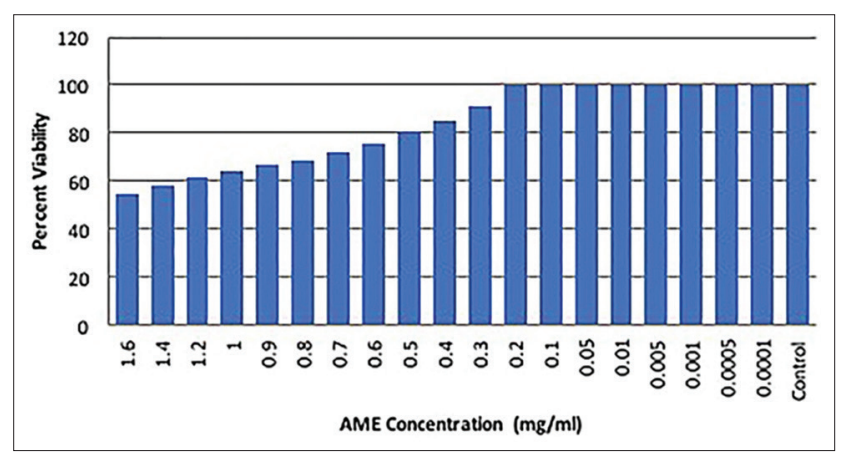

Figure-1: Non-cytotoxic dose of methanolic extract of Artemisia indica in chicken lymphocytes culture by 3-(4,5-dimethylthiazol-2-y1)-2,5-diphenyltetrazolium bromide cytotoxicity assay.

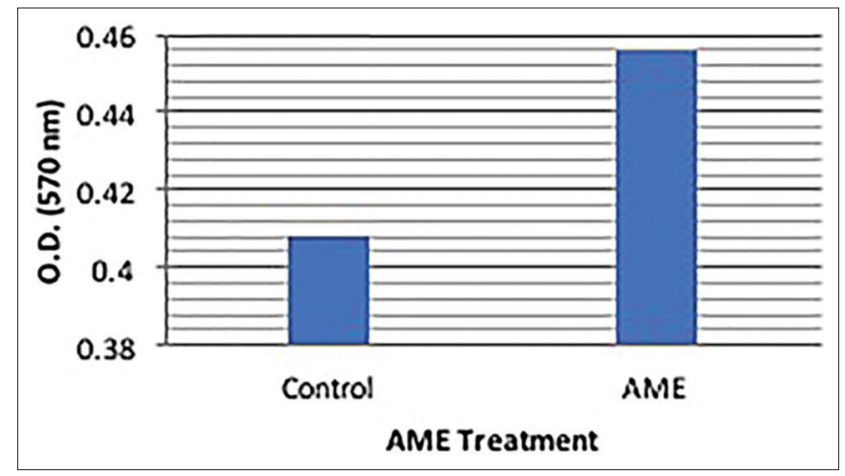

Figure-2: Effect of methanolic extract of Artemisia indica on $B$ cell proliferation in the presence of the mitogen (lymphocyte proliferation assay).

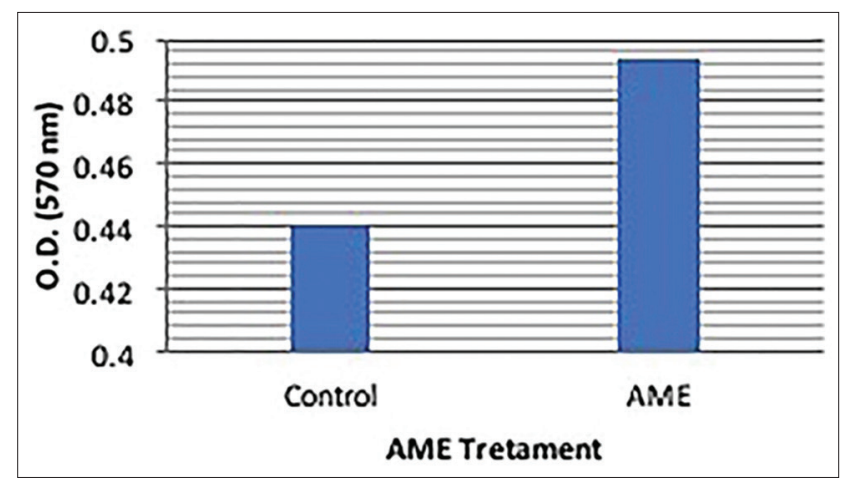

Figure-3: Effect of methanolic extract of Artemisia indica on $\mathrm{T}$ cell proliferation in the presence of the mitogen (concanavalin A).

Table-2: Effects of AME on B cell proliferation.

\begin{tabular}{lccc}
\hline Control/treatment & Mean OD $\mathbf{( 5 7 0} \mathbf{~ n m ) \pm S D ~}$ & \% proliferation & \% change in proliferative index \\
\hline Control & $0.408 \pm 0.006^{*}$ & 100 & 0 \\
Treatment with AME & $0.456 \pm 0.007^{*}$ & 111.76 & +11.76 \\
t value & 10.78253 & $*$ & \\
\hline
\end{tabular}

$* \mathrm{p}<0.05 . \mathrm{AME}=$ Artemisia indica methanol extract, $\mathrm{SD}=$ Standard deviation

Table-3: Effects of AME on T cell proliferation (Con A).

\begin{tabular}{lccc}
\hline Control/treatment & Mean OD $\mathbf{5 7 0} \mathbf{~ n m}) \pm$ SD & \% proliferation & \% change in proliferative index \\
\hline Control & $0.441 \pm 0.007^{*}$ & 100 & 0 \\
Treatment with AME & $0.494 \pm 0.007^{*}$ & 112.018 & +12.018 \\
$t$ value & 18.00912 & $*$ & \\
\hline
\end{tabular}

${ }^{*} \mathrm{p}<0.05 . \mathrm{AME}=$ Artemisia indica methanol extract, $\mathrm{SD}=$ Standard deviation 
properties [3]. Artemisia annua extracts contain Artemisinin, has the formula $\mathrm{C}_{15} \mathrm{H}_{22} \mathrm{O}_{15}$ and contains a peroxide bridge (C-O-O-C), have anti-inflammatory properties [11,24]. Methanol extracts of eight different Artemisia species showed anti-inflammatory activity in vitro [9]. The anti-inflammatory activity of the methanolic leaf extract of Artemisia vulgaris has been established using cotton pellet granuloma method [10]. Methanolic extract of aerial parts of A. vulgaris has potent analgesic and anti-inflammatory activities [25].

Even though "titépâti" (A. indica) has been used as an anti-inflammatory and adaptogen by the local people in Kumäuñ hills for human and animal use since ages, meager scientific literature is available on the immunomodulatory aspect of $A$. indica. The exhaustive literature search yielded only an isolated report of $A$. indica in which methanolic extract of $A$. indica was evaluated for anti-inflammatory action by carrageenin-induced rat paw edema and was reported to be anti-inflammatory and analgesic properties in a dose-dependent manner [26].

Cellular proliferation is an essential feature of the adaptive immune response. The lymphocyte proliferation is an important index to evaluate cellular immunity, and the lymphocyte proliferation rate can directly reflect the strength of cellular immunity [27]. As mentioned above, the LPA in the presence of AME and respective mitogens resulted in a significant $(p<0.05)$ upregulation of both B cells $(11.76 \%)$ and $\mathrm{T}$ cells $(12.018 \%)$ populations. Although no similar/ related report could be found regarding $A$. indica in the literature, there are relevant reports on few other species of Artemisia. The effects of methanolic extract and leaf powder of $A$. annua were studied on performance, cellular and humoral immunity in $240 \mathrm{Cobb}$ broiler chicks in a completely randomized design with the conclusion that the extract and leaf powder increases performance, cellular and humoral immunity of broilers [28]. Polysaccharide fractions purified from Artemisia selengensis and Artemisia iwayomogi exhibited immunomodulatory and antitumor properties [29] and extended the survival of murine spleen cells in vitro [30]. The immunomodulatory effects assessed by splenocyte proliferation and the cytokine secretion suggested the polysaccharides fractions from Moxa (Artemisia argyi) leaf are good immune enhancers [31].

Immunomodulatory activity of plants has been attributed eventually to the presence of various phytochemicals [32,33]. In general, there are at least two basic approaches which may be responsible to such activity, namely, these phytochemicals act directly on the mediators responsible for immune system or indirectly by the virtue of their antioxidative property. Probably, the actual mechanism of the immunomodulatory activity by these two basic approaches is mutually supportive and quite possibly synergistic as well [32]. Various plants derived compounds, namely, triterpenoids [34], flavonoids [35], saponins [36], or triterpenoid saponins [37] are reported to exhibit anti-inflammatory property. In one of our earlier reports pertaining to the qualitative and quantitative phytochemical evaluation of various extracts of $A$. indica, the AME revealed to possess various phytochemicals including major secondary metabolites, namely, carbohydrates, reducing sugars, amino acids, saponins, flavonoids, alkaloids, tannins, sterols, triterpenoids, phenolics, and glycosides [4].

Literature supports and suggests that there is a strong correlation between antioxidative properties of a plant and its immunomodulatory, particularly it's immunostimulatory potential [38-40]. It is now an established fact, that natural antioxidants from plants such as polyphenols play an important role in the protection of cells from oxidative damage and consequently induce anticancer activities including proapoptotic, DNA damaging antiangiogenic, and immunostimulatory effects [41].

Many studies suggest that endogenous antioxidants, or exogenous antioxidants present in the diet, can function as free radical scavengers and improve human and animal health $[42,43]$. There is an adequate amount of data indicating that the functions of the human immune system depend on the intake of micronutrients, which can act as antioxidants. Several clinical trials have found that antioxidant supplementation can significantly improve certain immune responses [44]. There are numerous reports which confirm the positive effects of natural flavonoids on immune system of different species, including chicken $[28,45,46]$. We have earlier demonstrated that AME is rich in phenolics with a total phenolic content of $255.5 \pm 6.71 \mathrm{mg}$ of GAE/g and a total flavonoid content of $161.2 \pm 4.95 \mathrm{mg}$ of QE/g [4]. We further evaluated the in vitro antioxidative potential of various extracts of $A$. indica through DPPH', $\mathrm{H}_{2} \mathrm{O}_{2}, \mathrm{NO}$ scavenging and total antioxidant capacity assays and here also AME exhibited significantly better antioxidant activity as compared to other extracts [47].

It has been pointed out that the improvement of innate resistance to infectious disease is one of the mechanisms for the achievement of better health status and higher productivity in poultry. The immune system could be activated not only through infectious agents but also through injection of LPSs isolated by bacteria $[48,49]$. The immunomodulatory role of plant polysaccharides is quite well described [50,51], including the anti-inflammatory effect [52]. Artemisia species used in traditional medicine have shown to contain polysaccharides with a wide variety of biological properties [53]. A water-soluble carbohydrate fraction isolated from $A$. iwayomogi has been reported to modulate the functional differentiation of bone marrow-derived dendritic cells [54] and showed immunomodulating and antitumor activities in mice [29]. Antitumor and immunomodulatory activities of a polysaccharide (FAAP-02) isolated from $A$. argyi 
were evaluated, and the results indicated that the antitumor activity of FAAP-02 might be associated with its immunostimulatory effects [55]. Polysaccharide fractions from $A$. tripartita exhibited potent phagocyte immunomodulatory activity, reactive oxygen species scavenging and complement-fixing activity [56]. The immunostimulating effects exhibited by AME through LPA could also be attributed to the polysaccharides either alone or in conjunction with various phenolics.

Here it is quite appropriate to mention an important consideration. It has been pointed out in the literature that according to diverse ethnomedicinal practices world over, especially the holistic approach of Ayurveda, the interplay of the various bioactive components and diverse biomolecules in a plant is of paramount importance in its medicinal and pharmaceutical activity [32]. The crude extracts of plants are pharmacologically more active than their isolated active principles probably due to the synergistic effects of various components present in the whole extract [57]. Another worthwhile consideration would be that according to epidemiological studies and trials on humans, it is evident that the health benefits of phytochemicals were observed predominantly when being consumed within their natural food matrices (fruits, vegetables, grain, etc.) [58].

Nevertheless, looking to the potential immunostimulatory activity of AME in chicken lymphocytes, it would be worthwhile to further evaluate/study the needed aspects such as the biomolecular fractionation studies and also bioavailability (absorption, metabolism and cellular, and tissue distribution) in a suitable system, establishing whether the in vitro effects are applicable to the situation in vivo. This would further pave the way to use/develop $A$. indica as a natural source of an immunomodulator and adaptogen in the form of a feed additive or food supplement for animals and humans.

\section{Conclusion}

Literature and ethnomedicinal experiences and beliefs support and suggest that members of genus Artemisia are excellent candidates to be developed into herbal immunomodulating source species/agent. Methanolic extract (AME) of $A$. indica, a plant used as a traditional medicine and animal feed in the Kumäuñ hills (Uttarakhand, India), was evaluated for its immunomodulatory potential employing standard LPA, and the results are indicative of the immunostimulatory potential of the plant. It would be worthwhile to further evaluate $A$. indica on relevant immunomodulatory aspects, especially the in vivo studies in a poultry system.

\section{Authors' Contributions}

PR, TKA, and PG equally contributed in the conceptualization and design of the experiment. PR and TKA equally contributed in the experimentation, analysis and interpretation of the data and manuscript preparation. All the authors read and approved the final manuscript.

\section{Acknowledgments}

The facilities/permissions provided by the Dean, College of Veterinary and Animal Sciences, G. B. Pant University of Agriculture and Technology, Pantnagar, and the Department of Biotechnology/Director research, GEU, Dehradun, Uttarakhand, India, is sincerely acknowledged. This study has not received any funding.

\section{Competing Interests}

The authors declare that they have no competing interests.

\section{References}

1. Ishizuka, M., Kawatsu, M., Yamashita, T., Ueno, M. and Takeuchi, T. (1995) Low molecular weight immunomodulators produced by microorganisms. Int. J. Immunopharmacol., 17: 133-139.

2. Rang, H.P., Dale, M.M., Ritter, J.M. and Moore, P.K. (2003) Pharmacology. $5^{\text {th }}$ ed. Churchill Livingstone, Edinburgh.

3. Ruwali, P., Gautam, P., Ambwani, S., Dadhich, A. and Ambwani, T.K. (2013) Immunomodulatory potential of genus Artemisia. J. Immunol. Immunopathol., 15(1): 99-101.

4. Ruwali, P., Ambwani, T.K., Gautam, P. and Thapliyal, A. (2015) Qualitative and Quantitative phytochemical analysis of Artemisia indica Willd. J. Chem. Pharm. Res., 7: 942-949.

5. Ruwali, P., Ambwani, T.K., Gautam, P. and Palni, L.M.S. (2017) Artemisia indica Willd. plant as a potential source of fodder and ethnoveterinary medicine in sheep and goat. In: National Seminar on 'Improvement of Small Ruminant Production System for Livelihood Security’, March 9-10, ICAR-CSWRI, Avikanagar, Rajasthan, SS4-33: 208-209.

6. Obistioiu, D., Cristina, R.T., Schmerold, I., Chizzola, R., Stolze, K., Nichita, I. and Chiurciu, V. (2014) Chemical characterization by GC-MS and in vitro activity against Candida albicans of volatile fractions prepared from Artemisia dracunculus, Artemisia abrotanum, Artemisia absinthium and Artemisia vulgaris. Chem. Cent. J., 8(6): $1-11$.

7. Shah, N.C. (2014) The economic and medicinal Artemisia species in India. Scitech. J., 1(1): 29-38.

8. Rather, M.A., Dar, B.A., Shah, W.A., Prabhakar, A., Bindu, K., Banday, J.A. and Qurishi, M.A. (2017) Comprehensive GC-FID, GC-MS and FT-IR spectroscopic analysis of the volatile aroma constituents of Artemisia indica and Artemisia vestita essential oils. Arabian J. Chem., 10: 3798-3803.

9. Choi, E., Park, H., Lee, J. and Kim, G. (2013) Anticancer, antiobesity, and anti-inflammatory activity of Artemisia species in vitro. J. Tradit. Chin. Med., 33(1): 92-97.

10. Afsar, S.K., Kumar, R., Gopal, J. and Raveesha, P. (2013) Assessment of anti-inflammatory activity of Artemisia vulgaris leaves by cotton pellet granuloma method in wistar albino rats. J. Pharm. Res., 7: 463-467.

11. Kim, W., Choi, W.J., Lee, S., Kim, W.J., Lee, D.C., Sohn, U.D., Shin, H. and Kim, W. (2015) Anti-inflammatory, antioxidant and antimicrobial effects of artemisinin extracts from Artemisia annua L. Korean J. Physiol. Pharmacol., 19: 21-27.

12. WHO. (2013) The WHO Traditional Medicine (TM) Strategy 2014-2023. World Health Organization, WHO Press, Geneva, Switzerland. p16.

13. Janossy, G. and Greaves, M.F. (1971) Lymphocyte 
activation: I.-Response of T and B lymphocytes to phytomitogens. Clin. Exp. Immunol., 9(4): 483-498.

14. Rose, N.R. and Friedman, H. (1976) Use of cell mediated lympholysis test in transplantation immunity. Manual of Clinical Immunology. American Society of Microbiology, Washington, USA. p851-857.

15. Boyse, E.A., Old, L.J. and Chouroulinkov, I. (1964) Cytotoxic test for demonstration of mouse antibody. Methods Med. Res., 10: 39-47.

16. Mosmann, T. (1983) Rapid colorimetric assay for cellular growth and survival: Application to proliferation and cytotoxicity assays. J. Immunol. Methods, 65: 55-63.

17. Lee, C.H., Kim, J.K., Kim, H.Y., Park, S.M. and Lee, S.M. (2009) Immunomodulating effects of Korean mistletoe lectin in vitro and in vivo. Int. Immunopharmacol., 9: $1555-1561$.

18. Snedecor, G.W. and Cochran, W.G. (1989) Statistical Methods. $8^{\text {th }}$ ed. Iowa State University Press, Iowa, USA.

19. Boardman, P.E., Sanz-Ezquerro, J., Overton, I.M., Burt, D.W., Bosch, E., Fong, W.T., Tickle, C., Brown, W.R.A., Wilson, S.A. and Hubbard, S.J. (2002) A comprehensive collection of chicken cDNAs. Curr. Biol., 12: 1965-1969.

20. Ali, M.M. (2015) Emerging prospective of Indian livestock: A study on poultry industry. Asian J. Manag. Sci., 4(1): 33-39.

21. Arreola, R., Quintero-Fabian, S., Lopez-Roa, R.I., FloresGutierrez, E.O., Reyes-Grajeda, J.P., Carrera Quintanar, L. and Ortuno-Sahagun, D. (2015) Immunomodulation and anti-inflammatory effects of garlic compounds. J. Immunol. Res., 2015: 401630.

22. Croteau, R., Kutchan, T.M. and Lewis, N.G. (2000) 'Natural products (secondary metabolites). In: Buchanan, B.B., Gruissem, W. and Jones, R.L., editors. 'Biochemistry and Molecular Biology of Plants', Chapter: 24, American Society of Plant Physiologists, Rockville, Maryland, USA. p1250-1318.

23. Leung, K.N., Leung, P.Y., Kong, L.P. and Leung, P.K. (2005) Immunomodulatory effects of esculetin (6,7-dihydroxycoumarin) on murine lymphocytes and peritoneal macrophages. Cell. Mol. Immunol., 2: 181-188.

24. Shi, C., Li, H., Yang, Y. and Hou, L. (2015) Antiinflammatory and immunoregulatory functions of artemisinin and its derivatives. Mediators Inflamm., 2015: 435713.

25. Ashok, P.K. and Upadhyaya, K. (2013) Evaluation of analgesic and anti-inflammatory activities of Aerial parts of Artemisia vulgaris L. in experimental animal models. $J$. Biol. Act. Prod. Nat., 3(1): 101-105.

26. Sagar, M.K., Ashok, P.K., Chopra, H. and Upadhyaya, K. (2010) Phytochemical and pharmacological potential of Artemisia indica in experimental models. Pharmacologyonline, 2: 1-4.

27. Li, C.R., Santoso, S. and Lo, D.D. (2007) Quantitative analysis of $\mathrm{T}$ cell homeostatic proliferation. Cell. Immunol., 250(1-2): 40-54.

28. Gholamrezaie, S.L., Mohammadi, M., Jalali-Sendi, J., Abolghasemi, S.A. and Roostaie, A.M.M. (2013) Extract and leaf powder effect of Artemisia annua on performance, cellular and humoral immunity in broilers. Iran. J. Vet. Res., 14: $15-20$.

29. Koo, K., Kwak, J., Lee, K., Zee, O., Woo, E., Park, H.K. and Youn, H.J. (1994) Antitumor and immunomodulating activities of the polysaccharide fractions from Artemisia selengensis and Artemisia iwayomogi. Arch. Pharm. Res., 17(5): 371-374.

30. Lee, K.R., Zee, O.P., Kwak, J.H., Kim, Y.S., Park, H.K., Koo, K.A. and Youn, H.J. (1993) The polysaccharide fractions of Artemisia species. Kor. J. Pharmacogn., 24: $289-295$

31. Lan, M.B., Zhang, Y.H., Zheng, Y., Yuan, H.H., Zhao, H.L. and Gao, F. (2010) Antioxidant and immunomodulatory activities of polysaccharides from Moxa (Artemisia argyi) leaf. Food Sci. Biotechnol., 19(6): 1463-1469.

32. Ambwani, T.K. (2013) In vitro evaluation of antioxidative, immunomodulatory and antiviral potential of Bacopa monnieri (Linn.) in Cell Culture System. PhD. Thesis, G.B. Pant University of Agriculture and Technology, Pantnagar, Uttarakhand, India.

33. Cundell, D.R. (2014) Herbal phytochemicals as immunomodulators. Curr. Immunol. Rev., 10(2): 1-18.

34. Fan, Y.M., Xu, L.Z., Gao, J., Wang, Y., Tang, X.H., Zhao, X.N. and Zhang, Z.X. (2004) Phytochemical and anti-inflammatory studies on Terminalia catappa. Fitoterapia, 75: 253-260.

35. Alcaraz, M.J. and Jimenez, M.I. (1988) Flavonoids as anti-inflammatory agents. Fitoterapia, 59: 25-38.

36. Bhargava, K.P., Gupta, M.B., Gupta, G.P. and Mitra, C.R. (1970) Anti-inflammatory activity of saponin and other natural products. Indian J. Med. Res., 58(6): 724-730.

37. Anam, E.M. (2001) Anti-inflammatory activity of compounds isolated from the aerial parts of Abrus precatorius (Fabaceae). Phytomedicine, 8: 24-27.

38. Russo, A., Izzo, A.A., Borrelli, F., Renis, M. and Vanella, A. (2003) Free radical scavenging capacity and protective effect of Bacopa monniera L. on DNA damage. Phytother. Res.,17: 870-875.

39. Bukharia, V., Charde, R. and Charde, M. (2010) Evaluation of ethanolic extract of Moringa oleifera for wound healing, anti-inflammatory and antioxidant activities on rats. In: International Conference on Folk and Herbal Medicine, November 5-27 (2010), M. S. University, Udaipur, PB-40. p180.

40. Bhati, P. and Charde, R. (2010) Antioxidant and anti-inflammatory activities of bark extract of Cassia fistula Linn. In: International Conference on Folk and Herbal Medicine, November 5-27 (2010), M. S. University, Udaipur, PB-38. p179.

41. Leong, A.C.N., Kinjo, Y., Tako, M., Iwasaki, H., Oku, H. and Tamaki, H. (2010) Flavonoid glycosides in the shoot system of okinawa taumu (Colocasia esculenta S). Food Chem., 119: 630-635.

42. Aruoma, O.I. (2003) Methodological considerations for characterizing potential antioxidant actions of bioactive components in food plants. Mutat. Res., 523-524: 9-20.

43. Valentao, P., Fernandes, E., Carvalho, F., Andrade, P.B., Seabra, R.M. and Bastos, M.L. (2002) Antioxidant activity of Hypericum androsaemum Infusion: Scavenging activity against superoxide radical, hydroxyl radical and hypochlorous acid. Biol. Pharm. Bull., 25(10): 1320-1323.

44. Bendich, A. (1993) Physiological role of antioxidant in the immune system. J. Dairy Sci., 76: 2789-2794.

45. Kong, X., Hu, Y., Rui, R., Wang, D. and Li, X. (2004) Effects of Chinese herbal medicinal ingredients on peripheral lymphocyte proliferation and serum antibody titer after vaccination in chicken. Int. Immunopharmacol., 4: 975-982.

46. Taheri, H.R., Rahmani, H.R. and Pourreza, J. (2005) Humoral immunity of broilers is affected by oil extracted propolis (OEP) in the diet. Int. J. Poult. Sci., 4: 414-417.

47. Ruwali, P., Ambwani, T.K. and Gautam, P. (2017) In vitro antioxidative potential of Artemisia indica willd. Indian J. Anim. Sci., 87(11): 1326-1331.

48. Oblakova, M.G., Sotirov, L.K., Lalev, M.T., Hristakieva, P., Mincheva, N., Ivanova, I., Bozakova, N.A. and Koynarski, T.S. (2015) Growth performance and natural humoral immune Status in broiler chickens treated with the immunomodulator natstim ${ }^{\circledR}$. Int. J. Curr. Microbiol. App. Sci., 4(11): 1-7.

49. Webel, D.M., Finck, B.N., Baker, D.H. and Jonson, R.W. (1997) Time course of increased plasma cytokines, cortisone and urea nitrogen in pigs following intraperitoneal injection of lipopolisaccharide. J. Anim. Sci., 75: 1514-1520.

50. Schepetkin, I.A. and Quinn, M.T. (2006) Botanical polysaccharides: Macrophage immunomodulation and therapeutic potential. Int. Immunopharmacol., 6: 317-333. 
51. Choque-Delgado, G.T., Tamashiro, W.M.S.C. and Pastore, G.M. (2010) Immunomodulatory effects of fructans. Food Res. Int., 43(5): 1231-1236.

52. Pereira, L., De, P., Da-Silva, R.O., Bringel, P.H., De, S.F., Da-Silva, K.E.S., Assreuy, A.M.S. and Pereira, M.G. (2012) Polysaccharide fractions of Caesalpinia ferrea pods: Potential anti-inflammatory usage. J. Ethnopharmacol., 139: 642-648.

53. Correa-Ferreira, M.L., Noleto, G.R. and Petkowicz, C.L.O. (2014) Artemisia absinthium and Artemisia vulgaris: A comparative study of infusion polysaccharides. Carbohydr. Polym., 102: 738-745.

54. Lee, J.A., Sung, H.N., Jeon, C.H., Gill, B.C., Oh, G.S., Youn, H.J. and Park, J.H. (2008) Carbohydrate fraction from Artemisia iwayomogi, modulate the functional differentiation of bone marrow-derived dendritic cells. Int. Immunopharmacol., 8(4): 534-541.
55. Bao, X., Yuan, H., Wang, C., Liu, J. and Lan, M. (2013) Antitumor and immunomodulatory activities of a polysaccharide from Artemisia argyi. Carbohydr. Polym., 98: 1236-1243.

56. Xie, G., Schepetkin, I.A., Siemsen, D.W., Kirpotina, L.N., Wiley, J.A. and Quinn, M.T. (2008) Fractionation and characterization of biologically-active polysaccharides from Artemisia tripartita. Phytochemistry, 69(6): 1359-1371.

57. Hamberger, M. and Hastettman, K. (1991) Bioactivity in plants: The link between phytochemistry and medicine. Phytochemistry, 30: 3864-3874.

58. Bouayed, J. and Bohn, T. (2010) Exogenous antioxidantsdouble-edged swords in cellular redox state. Health beneficial effects at physiologic doses versus deleterious effects at high doses. Oxid. Med. Cell. Longev., 3(4): 228-237. 